\title{
Determination of Iodide in Tropical Seaweed (halopterisfilicina)
}

\author{
Usman Lado Ali ${ }^{1}$, Nasruddeen Yusuf Al-awwal ${ }^{2}$ \\ ${ }^{1}$ Department of Chemistry, Northwest University, Kano, Kano-Nigeria \\ ${ }^{2}$ Department of Chemistry, SRM University, Kattankulathur-603203, India
}

\begin{abstract}
Seaweed (Halopterisfilicina) was analyzed for its iodide content. The iodide content ranges from0.081 to $0.121 \%$ of the dried weighed sample. Various factors were suspected inhibiting the iodide content. The oxidation method adopted employ the use of $30 \%$ hydrogen peroxide in acidic medium, subsequent extraction with chloroform and titration against $0.05 N$ Sodium Thiosulphate gave an average iodide content of $0.102 \%$ of the dried weighed sample.
\end{abstract}

Keywords: Seaweed, HalopterisFilicina, Iodide, Iodine, Tropical,Phaeophyceae

\section{Introduction}

Seaweeds are macroscopic member of the division Chlorophyta, Phaeophyta and Rhodophyta living in sea [1], [2]. As communities they are easy to recognize. They are plants visible to naked eyes, growing attached to the solid substrata between and below tide marks. Seaweed may occur in unattached state, as for example Sargasso Sea[3]. However, attached plants form the greater portion of the total seaweed stock of the world. The division Chlorophyta, Phaeophyta and Rhodophyta were noticed among the most beautiful in the world, especially the red algae (Rhodophyta). They are also academically and commercially interesting such interest they generate that an international symposium is convened in every three years to present information and ideas on their biology, chemistry and commercial significance [3].

Phaeophyta (brown algae) and Rhodophyta (red algae) are the most important as they display distinctions between themselves and others, (i.eChlorophyta and higher plants). These variations could be in color, environmental needs and composition [4].

\subsection{Rhodophyta}

Rhodophyta or red algae form a big group of highly specialized marine algae comprising about 3,000 species. They are distributed in both temperate and tropical seas particularly in the letter. They are however some parasitic and epiphytic varieties, which grow on other algae. Although marine, Rhodophyta are characteristically red or purplish in color due to the presence of red pigment called Phycoerythinwhich masks the present of chlorophyll. Many red algae contain phycocynin the blue pigment of cyanophyta. Examples are Polysiphonia and Batrachospermum[4].

\subsection{Phaeophyta}

Phaeophytaor brown algae are interesting group of seaweeds of forms and sizes, comparing of about 1,000 species [4]. They are distributed between tidal levels along the coast, predominantly of temperate seas. They are mostly attached to the rock or some other substrata. Some few are free floating. Their color range from brown to olive-green due to the present of brown pigment (fucoxanthin) in their chloroplast which masks the chlorophyll. Examples are Ectocarpus, Laminaria, Fucus, Sargassum and HalopterisFilicina.

\subsection{HalopterisFilicina}

HalopterisFilicinabelongs to the kindomChromalveolata, division of Hetrokontophyta, class of Phaeophyceae and order of Sphacelariales in family of Stypocaulaceae[5], [6]. It is a small algagrownto considerable height, having both root and central axis surrounded by cortex with alternately branched pinnate thalli. Very bushy and rigid [7].

Although iodine is a micro-element/nutrient required by several red and brown algae, its metabolic role is not clear [3]. Vines and Rees [8] reported that iodine is a microconstituent of all organisms but plentiful in seaweeds. Iodine exists as iodide in brown and red algae [3]. The presence of this iodide can be quantitatively detected as elemental iodine, the amount depend on many factors; species; whether is fruiting or sterile; locale; season of the year; the degree of exposure to seawater and wave action and temperature [3], [9]. The oar and rock weeds were initially the economic source of elemental iodine. Recovery of the element includes ashing the dried weed in beach kilms and extraction of the salts, followed by oxidation. Optimum yield depended upon avoiding loss of the iodine by leaching action of rainwater during drying and loss of free iodine before and during the ashing. The best seaweed Laminariadigitata, properly burnt contains $0.13-0.63 \%$ iodine, but value of over $4 \%$ been reported [10]. A quantitative result obtained from Japanese Sargassum was $0.05 \%$ [10]. Nuffield series of experiments [11],haveshown that an estimated maximum iodide concentration of $2 \%$ in $5 \mathrm{~g}$ of dried weed was reported [10]. Inkelps, $1 \%$ of the dry weight may be iodine [3].

\section{Sample collection and Preparation}

The seaweed sample was identified through the use of pictorial references provided in [7]. The sample was 


\section{International Journal of Science and Research (IJSR) \\ ISSN (Online): 2319-7064 \\ Index Copernicus Value (2013): 6.14 | Impact Factor (2013): 4.438}

collected from Lagos beach. Lagos State, Nigeria. The sample collected was dried under laboratory condition and pulverized to a fine powder.

\subsection{Procedure}

$1 \mathrm{~g}$ of the sample was weighed into a beaker and soaked with $30 \mathrm{~cm}^{3}$ of water for 24 hours. After 24 hours, the sample was filtered into $250 \mathrm{~cm}^{3}$-Erlenmeyer flask, the residue was washed with water, and the combined filtrate was diluted to $100 \mathrm{~cm}^{3}$ with water.

$20 \mathrm{~cm}^{3}$ portions of the filtrate were introduced into a separation funnel containing $5 \mathrm{~cm}^{3} \mathrm{CHCl}_{3}, 1 \mathrm{~cm}^{3} 3 \mathrm{MH}_{2} \mathrm{SO}_{4}$ and $30 \% \mathrm{H}_{2} \mathrm{O}_{2}$. The separation funnel with its content was agitated, following the separation of the two layers; the purple layer was drained into $250 \mathrm{~cm}^{3}$-Erlenmeyer flask. The extraction was repeated two more times to ensure the disappearance of the purple color from the organic layer. The purple color solution was titrated with standard sodium Thiosulphate solution. The end point was indicated by the disappearance of the purple color. The procedure was repeated within sample for concordant readings and using different sample weights.

In each case, the volume of the titrand used was determined and recorded. The amount of iodide in the $100 \mathrm{~cm} 3$ of the titrant was determined and the percentage of the iodine in the dried sample computed [12].

\subsection{Schemes of the Reactions:}

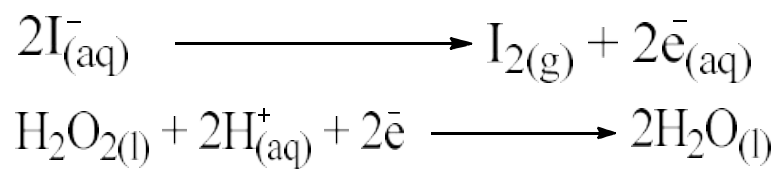

The overall is;

$2 \mathrm{H}_{2} \mathrm{O}_{2(\mathrm{l})}+2 \mathrm{H}_{(\mathrm{aq})}^{+}+2 \mathrm{I}_{(\mathrm{aq})}^{-} \longrightarrow \mathrm{I}_{2(\mathrm{l})}+2 \mathrm{H}_{2} \mathrm{O}_{(\mathrm{l})}$

Then, the iodine so generated will react with Sodium thiosulphite according to the equation.

$$
\begin{aligned}
& \mathrm{I}_{2(1)}+2 \mathrm{Na}_{2} \mathrm{~S}_{2} \mathrm{O}_{3(1)} \longrightarrow 2 \mathrm{NaI}_{(1)}+\mathrm{Na}_{2} \mathrm{~S}_{4} \mathrm{O}_{4} \\
& \text { Hence; } \\
& \quad \mathrm{a}=2 \\
& \mathrm{~b}=1
\end{aligned}
$$

The amount of the iodide in the $100 \mathrm{~cm}^{3}$ of the sample was calculated from the formula thus;

$$
\left(C m^{3} a\right)(M a) \frac{b}{a}\left(m o l . W t_{b}\right)=M g_{b}
$$

Where;

$\mathrm{Cm}^{3} \mathrm{a}=$ Volume of the titrant used

$\mathrm{Ma}=$ molarity of the titrant

$\mathrm{a}=$ number of moles of the titrand

$\mathrm{b}=$ number of moles of the titrant

Mol. $\mathrm{Wt}_{\mathrm{b}}=$ molecular weight of the titrant

$\mathrm{Mg}_{\mathrm{b}}=$ milligram of the titrant in $100 \mathrm{~cm}^{3}$ of the sample.

The percentage of the iodide in the dried sample was also calculated from the formula thus;

$$
\% \text { iodide }=\frac{\text { milligram of the iodide }}{\text { milligram of the dried sample }}
$$

Table 1: \%iodide in the sample

\begin{tabular}{|c|c|}
\hline Mass of the sample $(\mathrm{g})$ & \%Iodide in the dried weed \\
\hline 1 & 0.081 \\
2 & 0.121 \\
3 & 0.108 \\
4 & 0.101 \\
5 & 0.097 \\
\hline
\end{tabular}

\section{Result and Discussion}

Table (1) above depicts the \% and average (mean) \%iodide obtained from the HalopterisFilicina.Based on that, the seaweed (HalopterisFilicina) was found to have an appreciable amount $(0.102 \%)$ of iodide content when compared to what was earlier report for Laminariadigitata (0.13-0.63\%) and Japanese Sargssum (0.05\%) [10]. Though, compared to the recent development in research on these seaweeds (Laminariadigitata and Sargassum), were reported to have iodide content of $4 \%$ and $2 \%$ respectively [10], this considerable amount recovered rendered (HalopterisFilicina) to have poor iodide content. The low level of iodide in (HalopterisFilicina) may be due to the tropic nature of the environment (high temperature) and intense sun light which may thermally or photocalytically oxidizes the iodide and liberated it as elemental iodine to the environment. Other factors may include locale; degree of exposure to the water, wave action and whether it is fruiting or sterile.

\section{Conclusion}

Unlike Oarweeds and rockweeds which were the initial economic sources of elemental iodine [10], the HalopterisFilicina analyzed was low in iodide content and poor for economic exploitation of elemental iodine.

\section{References}

[1] Bold, H. C. Morphology of Plants. Harper Row Publishers, New York.Pp. 2-3, 1967.

[2] www.encyclopedialtopic $\backslash$ seaweed.aspx.

[3] Chapman, A. R. O., Biology of Seaweeds Level of Organization. Edward and Arnold, London. Pp. 17-20, 1979.

[4] Dutta, A. C. Botany for Degree Student Satribari Road Gauhati, Assam. Pp. 341-395, 1963

[5] Migula, W., Kryptogamen-Flora Von Deutchland, Deutch-Österreichund der Schweiz, Band II. Algen, 1909.

[6] Teil. Rhodophyceae, Phaeophceae, Characeae. Verlagfriedriech Von Zezschwtz,. 1909.

[7] www.habitas.org.uk/marinelife//species.asp?item=ZR43 2.

[8] Vines, A. E. and Rees, N., Plant and Animal Biology, $4^{\text {th }}$ Ed., Vol. II. Pitman Publishers, England. Pp. 105, 1972.

[9] Booney, A. D., A Biology of Marine Algae, Hutchinson Educational Ltd., London, ch. 4, 1966. 


\section{International Journal of Science and Research (IJSR) \\ ISSN (Online): 2319-7064}

Index Copernicus Value (2013): 6.14 | Impact Factor (2013): 4.438

[10] Chapman, V. J., Seaweed and Their uses, $2^{\text {nd }}$ Ed., Methuen and Co., Ltd., London. Pp. 42-43, 1970.

[11]Nuffield Foundation, Chemistry: Collected Experiments. Longmans.Green.and Co., Ltd., Pp. 46, 1968.

[12] Senyk, J. I., "Determination of Iodide in Seaweed, Journal of Chemical Education", Volume 54. Number 8, 551-552, 1977.

\section{Author Profile}

Usman Lado Ali, born on $3^{\text {rd }}$ March, 1982 at Getso Town, Gwarzo Local Government, Kano State, Nigeria. Graduated from Bayero University Kano, Nigeria and obtained B. Sc. Honor in Chemistry, 2006. Worked with KSSSSMB Kano, Science and Technical Schools Board, Kano and Currently graduate assistant at Northwest University Kano, as well as M.Sc. Chemistry Student at SRM

University, Kattankulathur-603203, India. 